\title{
Posição da Sociedade Brasileira de Enfermeiros Pediatras sobre as competências essenciais do enfermeiro neonatologista e pediatra
}

Desenvolvido pela Comissão Permanente de Educação e Pesquisa da SOBEP:

\section{Coordenadora:}

Maria Aparecida Munhoz Gaiva (D) https://orcid.org/0000-0002-8666-9738 Universidade Federal de Mato Grosso, Cuiabá, MT, Brasil.

\section{Membros da Comissão:}

Aline Silveira (D) https://orcid.org/0000-0003-4470-7529 Universidade de Brasília, Brasília, DF, Brasil.

Claudia Silveira Viera $\mathbb{C}_{\text {https://orcid.org/0000-0002-0900-4660 }}$

Universidade Estadual do Oeste do Paraná, Cascavel, PR, Brasil.

Edmara Bazoni Soares Maia (1) https://orcid.org/0000-0003-2996-6936

Escola Paulista de Enfermagem, Universidade Federal de São Paulo, SP, Brasil.

Jane Cristina Anders (1) https://orcid.org/0000-0002-9130-1073

Universidade Federal de Santa Catarina, Florianópolis, SC, Brasil.

Juliana de Oliveira Freitas Miranda (1) https://orcid.org/0000-0001-7659-3103

Universidade Estadual de Feira de Santana, Novo Horizonte, BA, Brasil.

Luciana Mara Monti Fonseca (D) https://orcid.org/0000-0002-5831-8789

Escola de Enfermagem de Ribeirão Preto, Universidade de São Paulo, Ribeirão Preto, SP, Brasil.

Mauren Teresa Grubisich Mendes Tacla (iㅐ https://orid.org/0000-0001-8928-3366

Universidade Estadual de Londrina, Londrina, PR, Brasil.

Monika Wernet 1 i https://orid.org/0000-0002-1194-3261

Universidade Federal de São Carlos, São Carlos, SP, Brasil.

Natália Del' Angelo Aredes (1D https://orcid.org/0000-0002-1661-8601

Universidade Federal de Goiás, Goiânia, GO, Brasil.

\section{Como citar:}

Sociedade Brasileira dos Enfermeiros Pediatras. Posição da Sociedade Brasileira de Enfermeiros Pediatras sobre as competências essenciais do enfermeiro neonatologista e pediatra. Rev Soc Bras Enferm Ped. 2020;20(2):116-33.

Autor correspondente: Maria Aparecida Munhoz Gaiva | E-mail: mamgaiva@gmail.com

Dol: http://dx.doi.org/10.31508/1676-3793202000016

\section{Introdução}

A Sociedade Brasileira de Enfermeiros Pediatras (SOBEP) tem como compromisso assumido em seu estatuto congregar os enfermeiros, que se interessem pela saúde da criança desde o seu nascimento até o final da adolescência, bem como incentivar, aperfeiçoar e difundir os conhecimentos da especialidade, promovendo condições de atualização permanente através da utilização dos melhores meios disponíveis, podendo conceder título de especialista após avaliação do candidato, promover cursos de especialização, treinamento, aperfeiçoamento e educação continuada e promover e incentivar a formação de especialistas através do ensino e pesquisa.

Nesse sentido a SOBEP entende que o enfermeiro generalista desempenha funções essenciais no contexto das práticas em saúde tais como cuidar, educar, coordenar, colaborar e supervisionar, o que requer desse profissional múltiplas competências, intimamente ligadas ao perfil profissional. Mas para atuar como especialista em uma determinada área é preciso avançar e incorporar outras habilidades e atitudes as quais precisam estar definidas. 
No Brasil observa-se uma lacuna na definição das competências do enfermeiro pediatra e do enfermeiro neonatologista e ausência de documento que as apontem. Dessa maneira, considerando que o cuidado de enfermagem nessas áreas demanda dos enfermeiros habilidades diferenciadas para elaborar estratégias de ação e interações necessárias para cuidar do neonato, da criança, do adolescente e de sua família em toda sua complexidade, justifica-se a elaboração de um documento que defina as competências essenciais e específicas desses profissionais, liderado pela Sociedade Brasileira de Enfermeiros Pediatras.

\section{Métodos}

A condução do trabalho de elaboração e validação das competências do enfermeiro pediatra e do neonatologista foi realizada pela Comissão de Educação e Pesquisa da SOBEP, que é composta por 10 membros.

Para o estabelecimento da estrutura conceitual, foram realizadas buscas na literatura nacional e internacional sobre o desenvolvimento de competências para os enfermeiros nas áreas de pediatria, neonatologia e enfermagem geral, seguido de leitura prévia pelos membros do grupo de trabalho. Após foram conduzidas reuniões por via remota com os membros da comissão para discutir os aspectos conceituais, a relevância, aplicabilidade, utilidade e pertinência das competências essenciais dos enfermeiros para atuação nas diversas áreas da pediatria e neonatologia, assim como para traçar os objetivos do documento.

A proposta apresentada tem como base o conceito de competência profissional como uma qualidade/capacidade individual em desempenhar uma função a partir de pré-requisitos essenciais. Assim, entende-se que: "Competência profissional consiste na capacidade em articular um conjunto de conhecimentos, habilidades, atitudes, experiência, valores e recursos externos para o desempenho eficaz do trabalho cotidiano." O foco da proposta está nas competências essenciais (Core Competencies ${ }^{1}$ ) que devem ser aplicadas à enfermagem neonatal e pediátrica, embora algumas delas possam ser implementadas em outras áreas da especialidade de enfermagem.

Os documentos que embasaram a construção das competências essenciais foram as políticas e os programas públicos voltadas para a saúde do neonato, ${ }^{(1)}$ criança e adolescente, ${ }^{(2)}$ o Código de Ética dos Profissionais de Enfermagem ${ }^{(3)} \mathrm{e}$ resoluções do COFEN, ${ }^{(4)}$ a Constituição Brasileira, ${ }^{(5)}$ o Estatuto da Criança e do Adolescente, ${ }^{(6)}$ as diretrizes do Cuidado Centrado no Paciente e na Família, ${ }^{(7)} \mathrm{o}$ Cuidado Desenvolvimental, o Cuidado Integral e Humanizado, ${ }^{(8)}$ os pressupostos do Brincar/ brinquedo terapêutico, ${ }^{(9,10)}$ da Segurança na Saúde ${ }^{(11)}$ e dos Valores Humanos, ${ }^{(12-14)}$ dentre outros. ${ }^{(15-17)}$

As etapas preconizadas na literatura para o processo de construção, adaptação e validação de instrumentos de medida em saúde, ${ }^{(18,19)}$ quais sejam, estabelecimento da estrutura conceitual; definição dos objetivos e da população envolvida; construção e estruturação do documento; e validação do conteúdo foram aplicadas, apesar de não se tratar de um instrumento de medida em saúde, mas de recomendações da SOBEP.

As competências essenciais do enfermeiro neonatologista e pediatra estão sustentadas em cinco habilidades: Habilidade em planejar o cuidado por meio da 
Sistematização da Assistência de Enfermagem; Habilidades Cognitivas; Habilidades Psico-Motoras; Habilidades Psicossociais e Habilidades em Tecnologia da Informação. Estas estão organizadas em cinco domínios: (1) Prática profissional, ética e legal; (2) Prática clínica; (3) Gestão, Liderança e Trabalho em equipe; (4) Pesquisa e produção de conhecimento e (5) Prática educativa, sendo domínio aqui definido como a área que inclui uma série de competências essenciais e necessárias para o exercício profissional.

Os domínios estão articulados com o Cuidado Centrado no Neonato, Criança, Adolescente e Família, cujos pressupostos centrais, dignidade e respeito, informação compartilhada, participação e colaboração devem nortear a atuação dos enfermeiros especialistas nos diversos espaços assistenciais de cuidado como na atenção primária à saúde, ambulatórios de seguimento, espaços de educação e de abrigamentos, serviços móveis de urgência e emergência, consultórios, e hospitais (alojamento conjunto, enfermarias, unidades de cuidado intermediário, centro cirúrgico, salas de recuperação anestésica e unidades de cuidados críticos).

A versão preliminar do documento foi apresentada e discutida na plenária do I Fórum de Consenso das Competências do Enfermeiro Pediatra e do Enfermeiro Neonatologista, no VIII Congresso Brasileiro de Enfermagem Pediátrica e Neonatal, em outubro de 2019. Participaram da discussão 81 enfermeiros, sendo 38 neonatologistas e 43 pediatras, que pontuaram suas sugestões, gerando a segunda versão do documento.

Na sequência foi realizada a validação de conteúdo por um painel composto por 21 enfermeiros experts (juízes) de diversas regiões do país, sendo 13 pediatras e 08 neonatologistas. Os critérios para a seleção dos juízes/experts foram: experiência mínima comprovada de três anos na área de pediatria/neonatologia (assistencial, gestão, ensino, pesquisa e/ou extensão).

A validade de conteúdo foi realizada pela técnica Delphi. Os experts avaliaram o documento individualmente e suas respostas foram consideradas para reformulação do mesmo até obtenção da concordância desejada de $90 \%$. $^{(20,21)}$

A partir da assinatura do Termo de Consentimento Livre e Esclarecido para participação na validação, os juízes receberam, por meio eletrônico, um arquivo contendo o formulário com dados de identificação, a segunda versão do documento denominado "competências essenciais de enfermeiros pediatras e neonatologistas para o cenário brasileiro" e o questionário com escala tipo Likert para a validação do conteúdo e sugestões julgadas pertinentes. O questionário foi composto por três tópicos que consideraram a aparência e clareza; abrangência e pertinência; e aplicabilidade.

Os resultados foram processados no Excel versão 2005 e a concordância entre os experts foi mensurada pelo Índice de Validade de Conteúdo (IVC), em que se obteve IVC geral de 0,96 nas competências dos enfermeiros pediatras e IVC geral de 0,98 nas competências dos enfermeiros neonatologistas.

As competências essenciais de enfermagem elaboradas norteiam as ações do enfermeiro e apresentam um modelo para o desenvolvimento dos conhecimentos, habilidades e atitudes necessárias à prática clínica da especialidade pediátrica e neonatal. A seguir são apresentadas as competências essenciais dos enfermeiros neonatologistas e dos enfermeiros pediatras. 


\section{Competências essenciais do enfermeiro neonatologista}

A Sociedade Brasileira de Enfermeiros Pediatras define o enfermeiro neonatologista como o profissional graduado em enfermagem, tendo sido aprovado em curso de especialização lato sensu ou curso de residência em enfermagem neonatológica e/ou obtido o Título de Especialista auferido pela SOBEP, que presta cuidados voltados para a prevenção de doenças e agravos, promoção, proteção e recuperação da saúde do neonato e de sua família.

\section{Domínio 1: Prática profissional, ética e legal}

Definição: combinação de conhecimento especializado, conhecimento filosófico, conhecimento teórico (normativos, deontológicos e científicos) e conhecimento prático, que leva em consideração os contextos e as pessoas envolvidas. Engloba a responsabilidade pela prática profissional, a atuação de acordo com a legislação e códigos de conduta da profissão e a atuação em defesa e efetivação dos direitos individuais do neonato e da família.

\begin{tabular}{|c|c|}
\hline Competências essenciais & Habilidades \\
\hline $\begin{array}{l}\text { Reconhece e maneja } \\
\text { questões ou dilemas } \\
\text { éticos no cuidado } \\
\text { neonatal. }\end{array}$ & $\begin{array}{l}\text { - Reconhece, protege e efetiva os direitos do neonato e da família. } \\
\text { - } \text { Respeita e promove a autonomia da família. } \\
\text { - } \text { Estabelece diálogo/comunicação efetiva intra e interprofissional. } \\
\text { - Estabelece diálogo/comunicação efetiva com o neonato e família. } \\
\text { - Utiliza o conhecimento ético (normas éticas e bases legais) para orientar sua conduta } \\
\text { - em prol do neonato e sua família. } \\
\text { - Utiliza o conhecimento sobre padrões éticos e legais relacionados aos direitos do } \\
\text { neonato e da família e aos avanços tecnológicos. } \\
\text { - Atua em conformidade com as leis e políticas públicas norteadoras da atenção integral } \\
\text { à saúde do neonato e sua família no Brasil. } \\
\text { - Integra normas da prática clínica e os padrões morais da sociedade na qual o neonato } \\
\text { e a família estão inseridos (valores, crenças espirituais, religiosas e culturais). } \\
\text { - Identifica situações de vulnerabilidade do neonato e da família. } \\
\text { - Protege e defende o neonato, implementando um cuidado que tem como principais } \\
\text { elementos: atenção, sensibilidade e habilidades de comunicação para direcionar o } \\
\text { cuidado e a defesa da saúde; respeitar, proteger e implementar os direitos do neonato; } \\
\text { e identificar soluções alternativas para a promoção de sua saúde. } \\
\text { - Identifica e concilia as necessidades do neonato com as necessidades da família } \\
\text { - Promove ativamente o bem-estar do neonato, famílias e comunidades. } \\
\text { - Concilia tecnologia (cuidado tecnológico) com valores associados ao cuidado } \\
\text { ético-relacional, que envolve o exercício da sensibilidade e da afetividade (estar } \\
\text { perto, confortar, proteger, respeitar a dignidade, a integridade, a autonomia, entre } \\
\text { outros). }\end{array}$ \\
\hline $\begin{array}{l}\text { Desenvolve uma prática } \\
\text { de enfermagem neonatal } \\
\text { sustentada na ética } \\
\text { profissional. }\end{array}$ & $\begin{array}{l}\text { - Demonstra conhecimento das normas de conduta e das bases para a atuação legal e } \\
\text { ética da enfermagem e do enfermeiro neonatologista. } \\
\text { - Demonstra sensibilidade ética: capacidade de reconhecer um problema ético ou os } \\
\text { aspectos éticos das situações, capacidade de interpretar as reações e sentimentos } \\
\text { do neonato e da família; capacidade de decidir com inteligência e compaixão com } \\
\text { base nos entendimentos dos códigos de conduta ética, aprendizado acadêmico e } \\
\text { autoconhecimento, capacidade de reflexão, decisão e ação responsável. } \\
\text { - Demonstra capacidade de reflexão ética: escolhe, busca e problematiza entre as várias } \\
\text { soluções possíveis, considerando os critérios de eficiência, eficácia e segurança, mas } \\
\text { também o equilíbrio entre custo e benefício, sobretudo as demandas de prioridade, } \\
\text { equidade e moralidade. } \\
\text { - Adota um comportamento ético: conduta geral reiterada, saber-fazer qualificado e } \\
\text { corporificado de se relacionar com os outros de maneira respeitosa, receptiva e que } \\
\text { apoia suas preocupações. } \\
\text { - Identifica e relata casos de prática insegura e má conduta profissional. } \\
\text { - Registra de forma adequada os cuidados prestados e usa documentação apropriada. }\end{array}$ \\
\hline
\end{tabular}




\begin{tabular}{|c|c|}
\hline Competências essenciais & Habilidades \\
\hline $\begin{array}{l}\text { Atua com } \\
\text { Responsabilidade Social }\end{array}$ & $\begin{array}{l}\text { Reconhece que os neonatos e famílias podem ser prejudicados por sua condição de } \\
\text { saúde ou social. } \\
\text { Reconhece a vulnerabilidade do neonato e da família e mobiliza recursos de apoio, } \\
\text { implementando ações de proteção e facilitação do acesso aos serviços sociais. } \\
\text { Atua como mediador no processo de cuidar dos neonatos: respeita, protege, defende a } \\
\text { saúde dos neonatos e apoia suas famílias e os contatos com os serviços de saúde. } \\
\text { Atua como agente facilitador na resolução de injustiças e iniquidades com base no } \\
\text { conhecimento e no papel que desempenha dentro do sistema social e de saúde. }\end{array}$ \\
\hline $\begin{array}{l}\text { Toma decisões pautadas } \\
\text { na ética }\end{array}$ & $\begin{array}{l}\text { - Toma decisões orientadas pelo conceito de “melhor interesse" do neonato, que envolve } \\
\text { a avaliação do equilíbrio proporcional entre os benefícios e os potenciais danos. } \\
\text { - Considera os interesses da família e trata-a com seriedade. } \\
\text { - Pauta suas ações nos princípios da bioética. } \\
\text { - Concilia as necessidades dos outros (especialmente da família) com as do neonato. } \\
\text { - Promove a “voz do neonato", considera a perspectiva do neonato. } \\
\text { - Presta informações adaptadas à capacidade de compreensão da família e respeita o } \\
\text { direito ao consentimento de forma independente. } \\
\text { - Fornece informações a família para que possa compreender os papéis/funções dos } \\
\text { membros da equipe de saúde e enfermagem e a assistência oferecida. } \\
\text { no princípio da reconciliação por meio de busca de entendimentos comuns. Estes } \\
\text { entendimentos comuns fornecem as bases para o desenvolvimento de acordos de } \\
\text { cuidado, reforçando simultaneamente o engajamento e a qualidade do relacionamento } \\
\text { entre paciente, família e equipe de saúde). }\end{array}$ \\
\hline
\end{tabular}

\section{Domínio 2: Prática clínica}

Definição: combinação de habilidades, conhecimentos e atitudes que o enfermeiro neonatologista deve ter para desempenhar as funções de sua competência na oferta do cuidado direto, seguro e de qualidade ao neonato e família, considerando-o em sua integralidade dentro do contexto clínico específico. Constitui-se ainda na capacidade de avaliar com precisão e criticamente as melhores opções de cuidado pautadas nas políticas públicas de saúde, na prática baseada em evidências e no emprego do raciocínio clínico, ao mesmo tempo em que incorpora atributos como comunicação eficaz, gerenciamento eficiente do tempo e delegação de demandas a outros profissionais da equipe quando necessário.

\begin{tabular}{|c|c|}
\hline Competências essenciais & Habilidades \\
\hline $\begin{array}{l}\text { Atua na prevenção de } \\
\text { doenças e agravos, } \\
\text { educação e promoção } \\
\text { da saúde, recuperação, } \\
\text { reabilitação e/ou paliação } \\
\text { do neonato nos diferentes } \\
\text { níveis de complexidade e } \\
\text { atenção dos contextos nos } \\
\text { quais trabalha. }\end{array}$ & $\begin{array}{l}\text { - Demonstra conhecimento sobre as políticas e os programas de saúde voltados } \\
\text { aos neonatos brasileiros, assim como as principais doenças e agravos que podem } \\
\text { acometê-los. } \\
\text { - Reconhece vulnerabilidades, riscos potenciais, necessidades e problemas de saúde } \\
\text { individuais e coletivos considerando o processo saúde-doença em suas diversas } \\
\text { dimensões (sociocultural, psicoemocional, biológica e ambiental). } \\
\text { - Avalia o neonato, conforme orientações das políticas e programas nacionais } \\
\text { voltados para à saúde dessa população. } \\
\text { - Promove o cuidado integral ao neonato e sua família por meio de ações articuladas } \\
\text { com os programas e políticas de promoção e proteção à saúde, como recomendado } \\
\text { pelo Ministério da Saúde do Brasil. } \\
\text { - Realiza consultas do enfermeiro direcionadas às situações de prevenção de doenças e } \\
\text { agravos, promoção, recuperação e reabilitação em saúde do neonato e sua familia. } \\
\text { - Emprega tecnologias leves e duras necessárias para execução das ações de } \\
\text { prevenção de doenças e agravos, educação e promoção da saúde, recuperação, } \\
\text { reabilitação e/ou paliação do neonato. } \\
\text { - Contribui para o planejamento e organização do seu contexto de trabalho. } \\
\text { - Mantém, sempre que possível e necessário, articulação com os serviços de } \\
\text { referência e contrarreferência. } \\
\text { Promove e permite a participação e decisão da família no processo de educação e } \\
\text { promoção da saúde, recuperação, reabilitação e/ou paliação do neonato a fim de } \\
\text { alcançar o seu bem-estar. } \\
\text { - Estabelece uma relação de ajuda com o neonato e família, por meio da } \\
\text { comunicação efetiva, de medidas para alívio do sofrimento e apoio aos familiares } \\
\text { frente à morte, no sentido de promover melhorias na sua qualidade de vida. }\end{array}$ \\
\hline
\end{tabular}


Continuação.

\begin{tabular}{|c|c|}
\hline Competências essenciais & Habilidades \\
\hline $\begin{array}{l}\text { Desenvolve raciocínio } \\
\text { e julgamento clínicos e } \\
\text { pensamento crítico para } \\
\text { planejar e implementar o } \\
\text { cuidado de Enfermagem } \\
\text { baseado em evidências } \\
\text { científicas e nas políticas } \\
\text { públicas de saúde do } \\
\text { neonato. }\end{array}$ & $\begin{array}{l}\text { - Utiliza ferramentas do cuidado a exemplo do pensamento crítico, prática reflexiva, } \\
\text { pesquisa, auditoria e avaliação. } \\
\text {. Desenvolve a prática clínica, a tomada de decisão e a resolução de problemas } \\
\text { baseados em evidências científicas e nas políticas públicas de saúde do neonato. } \\
\text {. Demonstra habilidade no uso de ferramentas eletrônicas e processamento de dados } \\
\text { para o cuidado de enfermagem. }\end{array}$ \\
\hline $\begin{array}{l}\text { Promove a Sistematização } \\
\text { da Assistência de } \\
\text { Enfermagem (SAE) para o } \\
\text { cuidado do neonato e sua } \\
\text { família. }\end{array}$ & $\begin{array}{l}\text { Emprega as etapas do processo de Enfermagem para SAE, a partir de pressupostos } \\
\text { teórico-metodológicos, a fim de promover o cuidado qualificado. } \\
\text {. Garante que a documentação escrita (registros) seja clara, concisa, oportuna e em } \\
\text { conformidade com os protocolos e diretrizes institucionais. } \\
\text {. Reconhece as necessidades e os problemas de saúde do neonato e sua família; } \\
\text { planeja, promove e avalia o cuidado em suas diversas dimensões (sociocultural, } \\
\text { psicoemocional, biológica e ambiental) por meio da SAE. }\end{array}$ \\
\hline $\begin{array}{l}\text { Segue as diretrizes e } \\
\text { protocolos da Política } \\
\text { Nacional de Segurança do } \\
\text { Paciente (PNSP). }\end{array}$ & $\begin{array}{l}\text { Demonstra conhecimento sobre PNSP. } \\
\text { pesenvolve suas práticas de cuidado pautadas nas diretrizes e protocolos da PNSP } \\
\text { paramover a segurança do paciente neonatal nos serviços de atenção à saúde. }\end{array}$ \\
\hline $\begin{array}{l}\text { Demonstra proficiência } \\
\text { técnica e domínio das } \\
\text { especificidades do cuidado } \\
\text { ao neonato nos espaços de } \\
\text { atenção em que atua. }\end{array}$ & $\begin{array}{l}\text { Demonstra conhecimento abrangente de enfermagem na saúde do neonato, } \\
\text { baseado em evidências e apoiado na utilização do conhecimento apreendido na } \\
\text { área de formação e na experiência clínica. } \\
\text {. Demonstra domínio nas habilidades clínicas especializadas para promover a } \\
\text { assistência, assim como, de habilidades técnicas para gerenciar tecnologias leves e } \\
\text { duras necessárias no seu espaço de cuidado. } \\
\text { - Segue normas e protocolos de atendimento específicos para o cuidado ao neonato, } \\
\text { construídos conforme a necessidade dos distintos níveis de atenção do sistema de } \\
\text { saúde e com a finalidade de organizar a assistência, padronizar as ações e alcançar } \\
\text { a qualidade do cuidado prestado. } \\
\text { Desempenha atividades de cuidado para com o neonato e família privativas do } \\
\text { enfermeiro e supervisiona aquelas delegadas aos demais membros da equipe. }\end{array}$ \\
\hline $\begin{array}{l}\text { Articula saberes } \\
\text { interdisciplinares } \\
\text { necessários à execução do } \\
\text { cuidado ao neonato e sua } \\
\text { família. }\end{array}$ & $\begin{array}{l}\text { Estabelece a comunicação necessária e efetiva com os membros da sua equipe, } \\
\text { com os outros profissionais do seu serviço e dos demais serviços de atenção do } \\
\text { sistema de saúde, com os gestores e com os setores da sociedade, como estratégia } \\
\text { para articular os saberes em prol do planejamento do cuidado voltado ao neonato e } \\
\text { sua família no processo saúde-doença. }\end{array}$ \\
\hline $\begin{array}{l}\text { Estabelece relações } \\
\text { interpessoais e comunica-se } \\
\text { com o paciente, a família e } \\
\text { a equipe multiprofissional } \\
\text { a fim de promover } \\
\text { alinhamento do plano } \\
\text { terapêutico e estimular } \\
\text { o vínculo entre família, } \\
\text { paciente e equipe. }\end{array}$ & $\begin{array}{l}\text {. Utiliza comunicação efetiva, escuta ativa e relações respeitosas com o neonato, } \\
\text { família e equipe multiprofissional na prestação do cuidado em todos os níveis de } \\
\text { atenção à saúde. } \\
\text {. Estabelece diálogo com a equipe multiprofissional para promoção do planejamento } \\
\text { terapêutico adequado. } \\
\text { - Desenvolve trabalho em equipe e estabelece relação com profissionais de outros } \\
\text { setores do sistema de saúde. }\end{array}$ \\
\hline $\begin{array}{l}\text { Promove o cuidado } \\
\text { ético, legal, seguro, com } \\
\text { qualidade, equidade e } \\
\text { diversidade, ao neonato em } \\
\text { seus contextos de cuidado. }\end{array}$ & $\begin{array}{l}\text { Demonstra consciência e respeito pelos direitos legais dos neonatos. } \\
\text {. Respeita os princípios da bioética. } \\
\text { Emprega o cuidado desenvolvimental como mecanismo protetivo e promotor do } \\
\text { desenvolvimento infantil saudável. }\end{array}$ \\
\hline $\begin{array}{l}\text { Planeja, realiza e avalia } \\
\text { ações de educação e } \\
\text { vigilância em saúde de } \\
\text { maneira compartilhada, com } \\
\text { a família e/ou coletividade, } \\
\text { visando à construção } \\
\text { de conhecimentos para } \\
\text { o cuidado do neonato } \\
\text { no domicílio, mudanças } \\
\text { no estilo e condições de } \\
\text { vida e para estimular a } \\
\text { participação e o controle } \\
\text { social em saúde. }\end{array}$ & $\begin{array}{l}\text { Desenvolve ações de educação e vigilância em saúde para neonatos e suas famílias } \\
\text { nos cenários de atenção, de acordo com as suas necessidades individuais e/ou } \\
\text { coletivas. } \\
\text {. Utiliza estratégias pedagógicas com base no diálogo com a família e na escuta ativa. } \\
\text {. Desenvolve práticas de cuidado aliadas a educação em saúde no seguimento ao } \\
\text { neonato nos primeiros anos de vida. }\end{array}$ \\
\hline
\end{tabular}




\section{Domínio 3: Gestão, Liderança e Trabalho em equipe}

Definição: capacidade de organizar equipes e serviços de saúde materno-infantil. O domínio inclui as competências que indicam a capacidade de comunicação dentro das estruturas organizacionais e monitorar e organizar a entrega de cuidados de saúde eficazes para neonatos e suas famílias. As competências também podem incluir a participação no desenvolvimento de normas, políticas e atividades de qualidade específicas para a saúde dos neonatos e suas famílias.

\begin{tabular}{|c|c|}
\hline Competências essenciais & Habilidades \\
\hline $\begin{array}{l}\text { Comanda, dirige, } \\
\text { influencia e motiva } \\
\text { pessoas e grupos } \\
\text { de forma positiva no } \\
\text { intuito de alcançar um } \\
\text { objetivo em comum } \\
\text { estimulando a iniciativa e } \\
\text { responsabilização. }\end{array}$ & $\begin{array}{l}\text { - Promove o senso de coletividade, pertencimento e de colaboração da equipe. } \\
\text { - Estimula a iniciativa, e a proatividade, bem como a autonomia, delegando as tarefas a } \\
\text { serem realizadas e compartilhando as responsabilidades com a equipe. } \\
\text { - Orienta e supervisiona a equipe de enfermagem. } \\
\text { - Estimula o aprimoramento da equipe por meio da educação permanente. } \\
\text { - junto com a equipe estratégias de melhorias. } \\
\text { - Propõe escalas diárias e mensais da equipe de enfermagem, distribuindo os } \\
\text { profissionais segundo seus conhecimentos, habilidades e atitudes. } \\
\text { - Aplica ferramenta para avaliação de desempenho profissional da equipe de enfermagem. } \\
\text { - Participa de ação política em nível local, estadual ou nacional para promover a saúde } \\
\text { de neonatos e suas famílias. } \\
\text { - Participa na tomada de decisão em grupo. } \\
\text { - Compreende os padrões profissionais da prática, a avaliação da prática e a } \\
\text { responsabilidade pelo resultado da prática. }\end{array}$ \\
\hline $\begin{array}{l}\text { Gerencia os profissionais, } \\
\text { adotando modelos de } \\
\text { gestão que corroborem } \\
\text { para o desenvolvimento } \\
\text { da equipe, identificando } \\
\text { suas competências } \\
\text { e organizando o seu } \\
\text { processo de trabalho. } \\
\text { Além disso, administra } \\
\text { os recursos materiais } \\
\text { e financeiros, como } \\
\text { aquisição, distribuição, } \\
\text { alocação e faturamento } \\
\text { adequado dos recursos } \\
\text { para a organização } \\
\text { dos serviços de saúde } \\
\text { com o intuito de } \\
\text { garantir atendimento de } \\
\text { qualidade ao usuário. }\end{array}$ & 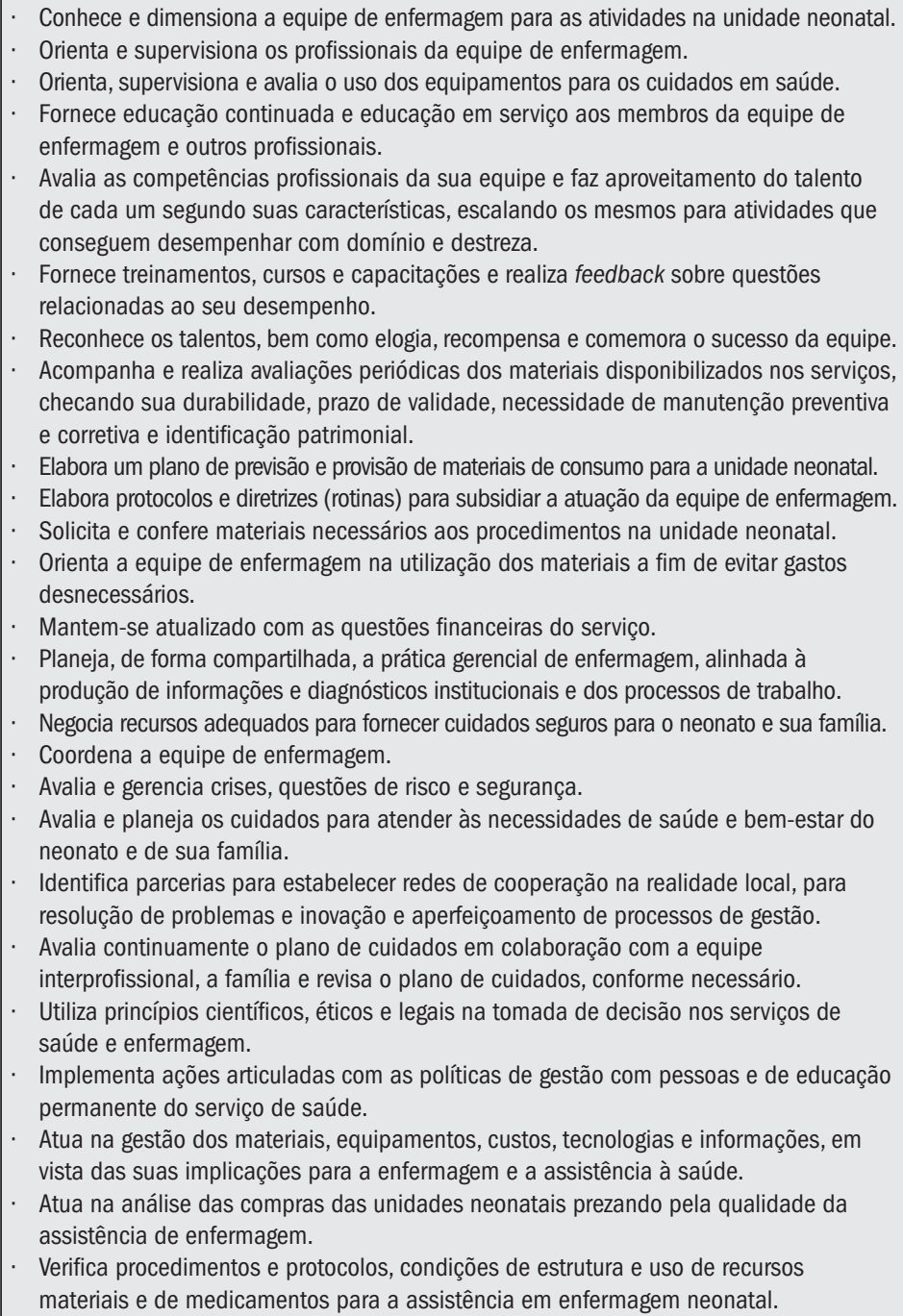 \\
\hline
\end{tabular}


Continuação.

\begin{tabular}{|c|c|}
\hline Competências essenciais & Habilidades \\
\hline $\begin{array}{l}\text { Realiza atividades em } \\
\text { conjunto com outros } \\
\text { profissionais que } \\
\text { possuem diferentes } \\
\text { funções/e papeis, } \\
\text { procurando articulá-los } \\
\text { entre si para o cuidado } \\
\text { integral do neonato e sua } \\
\text { família. }\end{array}$ & $\begin{array}{l}\text { - Articula-se com as diferentes equipes em prol do cuidado integral, seguro e de } \\
\text { qualidade do neonato e sua família. } \\
\text { - Interage com diferentes equipes dentro e fora do serviço, segundo as necessidades do } \\
\text { - É ativo e cooperativo, bem como dinâmico enquanto componente do grupo a que } \\
\text { pertence. } \\
\text { Compartilha informações e conhecimento pertinentes ao serviço e coloca-se a } \\
\text { disposição para ajudar sua equipe e as demais. } \\
\text { - Contribui para o fortalecimento da cultura de grupo, mantendo um bom ambiente de } \\
\text { trabalho. } \\
\text { Orienta a equipe de enfermagem quanto aos cuidados que deverão ser efetivados ao } \\
\text { neonato e sua família visando sua recuperação. } \\
\text { Delega responsabilidades à equipe e supervisiona o serviço prestado ao neonato e família. } \\
\text { Participa de processos de autoavaliação, demonstrando assertividade, flexibilidade, } \\
\text { confiança e sensibilidade aos efeitos da mudança. } \\
\text { Demonstra participação efetiva em equipes interdisciplinares. } \\
\text { Demonstra habilidades efetivas para organizar, participar e liderar grupos. } \\
\text { Reconhece os aspectos subjetivos, técnico-científicos, ético-políticos e socioeducativos } \\
\text { dos processos de trabalho em saúde e, especificamente, em enfermagem. } \\
\text { Emprega a comunicação nos processos de trabalho em saúde e em enfermagem. } \\
\text { envolvidos. } \\
\text { Participa de grupos de discussão interdisciplinar, a fim de buscar estratégias de } \\
\text { melhoria da qualidade da assistência prestada. }\end{array}$ \\
\hline
\end{tabular}

\section{Domínio 4: Pesquisa e produção de conhecimento}

Definição: refere-se aos métodos científicos e às exigências ético-legais na produção de saberes em saúde e enfermagem. Indicam a capacidade de buscar materiais científicos bem como socializá-los e utilizá-los criticamente na prática, fortalecendo a implementação de boas práticas e o compartilhamento de sua produção do conhecimento com a comunidade acadêmica e sociedade em geral, ampliando o desenvolvimento da ciência da enfermagem.

\begin{tabular}{|c|c|}
\hline Competências essenciais & Habilidades \\
\hline $\begin{array}{l}\text { Apresenta domínio de busca, } \\
\text { leitura e análise de textos } \\
\text { científicos. }\end{array}$ & 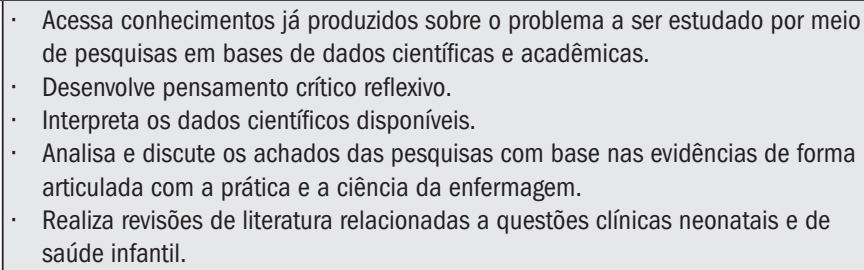 \\
\hline $\begin{array}{l}\text { Realiza observação crítica e } \\
\text { investigativa da realidade. }\end{array}$ & $\begin{array}{l}\text { Reconhece e problematiza as situações prioritárias da realidade profissional que } \\
\text { demandam a produção de conhecimento científico. } \\
\text {. Discute no âmbito coletivo os problemas e as potenciais soluções a serem } \\
\text { investigadas e obtidas por meio da pesquisa. } \\
\text {. Adota postura investigativa para nortear a prática clínica. }\end{array}$ \\
\hline $\begin{array}{l}\text { Demonstra criatividade para } \\
\text { propostas de melhoria do } \\
\text { cuidado e rotinas nas áreas } \\
\text { em que atua. }\end{array}$ & $\begin{array}{l}\text { - Considera e sintetiza as sugestões do coletivo (profissionais e usuários) para } \\
\text { implementação de melhores práticas nas ações em saúde. } \\
\text { - Identifica exemplos de projetos de intervenção exitosos e analisa viabilidade de } \\
\text { implementação em seu contexto, adaptando à sua realidade. }\end{array}$ \\
\hline $\begin{array}{l}\text { Busca atualização constante } \\
\text { de seus saberes e de sua } \\
\text { equipe por meio de evidências } \\
\text { científicas. }\end{array}$ & $\begin{array}{l}\text { Fundamenta sua prática em evidências científicas, tendo em vista a sua } \\
\text { incorporação no cotidiano do trabalho. } \\
\text { - Utiliza instrumentos científicos e metodológicos para resolução dos problemas } \\
\text { identificados na realidade. } \\
\text { - Socializa o conhecimento produzido nos diversos cenários como serviços de } \\
\text { saúde, comunidade acadêmica e sociedade em geral. } \\
\text { - Discute suas ideias de forma fundamentada e acolhe críticas e sugestões para } \\
\text { a melhoria do estudo, com habilidades de argumentação e reconhecimento da } \\
\text { importância da construção coletiva do conhecimento. } \\
\text { - Realiza leitura de artigos publicados em periódicos/revistas científicas. }\end{array}$ \\
\hline
\end{tabular}


Continuação.

\begin{tabular}{|l|l|}
\hline Competências essenciais & Habilidades \\
\hline $\begin{array}{l}\text { Produz evidências científicas } \\
\text { a partir de métodos e práticas } \\
\text { de pesquisa. }\end{array}$ & $\begin{array}{l}\text { Embasa sua produção do conhecimento considerando as demandas de seu } \\
\text { contexto de atuação. }\end{array}$ \\
& $\begin{array}{l}\text { Participa de projetos de pesquisa, quando disponíveis no contexto de atuação, } \\
\text { nas diferentes etapas, utilizando método científico e princípios éticos para a } \\
\text { produção do conhecimento. } \\
\text { Desenvolve textos baseados em evidências científicas para suporte de } \\
\text { atividades de educação, assistência e gestão. }\end{array}$ \\
\hline $\begin{array}{l}\text { Produz novos instrumentos/tecnologias que contribuam para a melhor prática } \\
\text { assistencial e o processo de trabalho da equipe de enfermagem. }\end{array}$ \\
\hline $\begin{array}{l}\text { Protege os direitos dos } \\
\text { envolvidas em pesquisa e/ou } \\
\text { outras intervenções. }\end{array}$ & $\begin{array}{l}\text { Conduz ações em pesquisa envolvendo neonatos e famílias com ética e suporte, } \\
\text { considerando a vulnerabilidade da população neonatal. } \\
\text { Obtém consentimento verbal e por escrito dos pais/responsáveis dos neonatos, } \\
\text { quando aplicável, antes de iniciar a pesquisa. }\end{array}$ \\
\hline
\end{tabular}

\section{Domínio 5: Prática educativa}

Definição: baseada na concepção da educação permanente em saúde e continuada no ambiente de trabalho direcionadas a si próprio, colegas de trabalho e estudantes, utilizando as habilidades de aprendizagem com autonomia. Realiza ações de educação em saúde em todos os contextos, articulando o uso de diferentes abordagens, estratégias e tecnologias para garantir melhor eficácia da troca de conhecimentos e oferta de informações sobre saúde com a família do neonato.

\begin{tabular}{|c|c|}
\hline Competências essenciais & Habilidades \\
\hline $\begin{array}{l}\text { Busca constantemente } \\
\text { aprimorar os conhecimentos } \\
\text { para subsidiar sua prática. }\end{array}$ & $\begin{array}{l}\text { - Utiliza estratégias de busca e análise de materiais de estudo. } \\
\text { - Constrói constantemente novos saberes. } \\
\text { avancicipa de atividades profissionais para promover o desenvolvimento e o } \\
\text { avara do enfermeiro neonatologista. }\end{array}$ \\
\hline $\begin{array}{l}\text { Fomenta ações de educação } \\
\text { permanente em saúde e de } \\
\text { educação continuada junto aos } \\
\text { colegas de trabalho. }\end{array}$ & $\begin{array}{l}\text { Reconhece as potencialidades e dificuldades da equipe de enfermagem } \\
\text { relacionadas com o desenvolvimento de suas competências profissionais. } \\
\text { - Identifica o processo de trabalho na equipe multiprofissional e promove } \\
\text { estudos de aprimoramento com foco no neonato e sua família. } \\
\text { - Age na perspectiva construtivista da educação, reconhecendo as vantagens } \\
\text { da construção coletiva do saber, do uso das metodologias ativas, baseadas } \\
\text { nos desafios do contexto do trabalho, pautadas na valorização dos pares e } \\
\text { nas evidências científicas. } \\
\text { - Lidera e encoraja outras lideranças para estabelecer e fortalecer a cultura } \\
\text { da educação permanente em saúde, promovendo ativamente o envolvimento } \\
\text { e a motivação dos pares. } \\
\text { - Participa em pares de processos de auto avaliação, demonstrando } \\
\text { assertividade, flexibilidade, confiança e sensibilidade aos efeitos da } \\
\text { mudança. } \\
\text { - Demonstra compromisso ativo para continuar o desenvolvimento de sua } \\
\text { própria educação e formação profissional. } \\
\text { Identifica as necessidades de aprendizagem da equipe que surgem no } \\
\text { cotidiano do cuidado ao neonato e familiares. } \\
\text { Incorpora os resultados dos processos de avaliação de desempenho em sua } \\
\text { própria prática. } \\
\text { Contribui para as experiências de aprendizagem de estudantes e novos } \\
\text { funcionários por meio de preceptoria/mentoria. } \\
\text { Contribui para as experiências de aprendizagem e desenvolvimento } \\
\text { profissional de si e dos outros. }\end{array}$ \\
\hline
\end{tabular}


Continuação.

\begin{tabular}{|c|c|}
\hline Competências essenciais & Habilidades \\
\hline Realiza educação em saúde. & $\begin{array}{l}\text { Planeja ações individuais e coletivas de educação em saúde, de acordo com o } \\
\text { - } \text { Contexto e demandas da população. } \\
\text { - } \quad \text { Identifica as necessidades de aprendizagem relacionadas à saúde dos neonatos } \\
\text { e familiares. } \\
\text { - } \text { Reconhece os fatores que afetam a saúde e as ações apropriadas a serem } \\
\text { tomadas para a promoção da saúde. } \\
\text { - } \text { Fornece à família informações e opções que lne permita tomar decisões } \\
\text { - } \text { Ajuda a família a reconhecer e compreender o estado de saúde atual do } \\
\text { neonato e as mudanças na sua saúde. } \\
\text { - Avalia a prontidão da família para aprender e fornece tempo suficiente para } \\
\text { ensinar de forma eficaz. } \\
\text { Valoriza o saber popular e dialoga com ele à luz das evidências científicas, } \\
\text { visando à autonomia de cuidado à saúde dos neonatos e famílias. } \\
\text { Utiliza abordagens, estratégias e tecnologias diversas para promover } \\
\text { aprendizagem em saúde para que os familiares realizem os cuidados } \\
\text { necessários ao neonato e sua família. } \\
\text { Trabalha em parceria com outros profissionais de saúde, agentes comunitários } \\
\text { de saúde, clientes, famílias e a comunidade na prevenção de doenças, } \\
\text { promoção e proteção da saúde do neonato. }\end{array}$ \\
\hline $\begin{array}{l}\text { Promove comunicação clara e } \\
\text { eficaz nos processos educativos, } \\
\text { favorecendo a construção de } \\
\text { conhecimento. }\end{array}$ & $\begin{array}{l}\text { Utiliza linguagem adequada ao entendimento de acordo com o nível de } \\
\text { compreensão, proficiência e literacia dos pais e dos membros da família, } \\
\text { possibilitando à família tomar decisões sobre a saúde de seus filhos. } \\
\text { - Alinha comunicação não verbal à comunicação verbal. } \\
\text { Valoriza na comunicação o tom de voz e postura corporal adequados, equilíbrio } \\
\text { entre ações de ouvir e falar, escuta ativa, esclarecimento de dúvidas e feedback, } \\
\text { valorização das diferentes culturas e considera contexto de ambiência. } \\
\text { - Reconhece as famílias como parceiros da equipe de saúde no planejamento } \\
\text { dos cuidados e utiliza as habilidades de comunicação para produzir os melhores } \\
\text { resultados em saúde. } \\
\text { Realiza registro completo das condições de saúde dos neonatos em prontuário, } \\
\text { contemplando aspectos que envolvam a família nas anotações. }\end{array}$ \\
\hline
\end{tabular}

\section{Competências essenciais do enfermeiro pediatra}

A Sociedade Brasileira de Enfermeiros Pediatras (SOBEP) define o Enfermeiro pediatra como o profissional graduado em enfermagem, tendo sido aprovado em curso de especialização lato sensu ou curso de residência em enfermagem pediátrica e/ou obtido o Título de Especialista auferido pela SOBEP, que presta cuidados voltados para prevenção de doenças e agravos, promoção, proteção e recuperação da saúde da criança, adolescente e sua família.

\section{Domínio 1: Prática profissional, ética e legal}

Definição: combinação de conhecimento especializado, conhecimento filosófico, conhecimento teórico (normativos, deontológicos e científicos) e conhecimento prático, que leva em consideração os contextos e pessoas envolvidas. Envolve a responsabilidade pela prática profissional, a atuação de acordo com a legislação e códigos de conduta da profissão e a atuação em defesa e efetivação dos direitos individuais da criança/adolescente e da família. 


\begin{tabular}{|c|c|}
\hline Competências essenciais & Habilidades \\
\hline $\begin{array}{l}\text { Reconhece e maneja } \\
\text { questões ou dilemas } \\
\text { éticos no cuidado } \\
\text { pediátrico. }\end{array}$ & $\begin{array}{l}\text { Reconhece, protege e efetiva os direitos da criança, do adolescente e da familia. } \\
\text { - Respeita e promove a autonomia da criança, do adolescente e da familia. } \\
\text { - } \text { Fornece informações suficientes e adequadas para a criança, o adolescente e a família. } \\
\text { - Estabelece diálogo/comunicação efetiva intra e interprofissional. } \\
\text { - } \text { Utiliza o conhecimento ético (normas éticas e bases legais) para orientar sua conduta em prol } \\
\text { da criança, do adolescente e da família. } \\
\text { - Utiliza o conhecimento sobre padrões éticos e legais relacionados aos direitos da criança, do } \\
\text { adolescente, da família e aos avanços tecnológicos. } \\
\text { Atua em conformidade com leis e políticas públicas norteadoras da atenção integral à saúde } \\
\text { da criança e do adolescente no Brasil. } \\
\text { Integra normas da prática clínica e os padrões morais da sociedade na qual a criança, o } \\
\text { adolescente e a família estão inseridos (valores, crenças espirituais, religiosas e culturais). } \\
\text { Identifica situações de vulnerabilidade da criança, do adolescente e da famîlia. } \\
\text { - Protege e defende a criança e o adolescente implementando um cuidado que tem como } \\
\text { principais elementos: atenção, sensibilidade e habilidades de comunicação para direcionar } \\
\text { o cuidado e a defesa da saúde; respeitar, proteger e implementar os direitos da criança; e } \\
\text { identificar soluções alternativas para a promoção de sua saúde. } \\
\text { Identifica e concilia as necessidades da criança e do adolescente com as necessidades da } \\
\text { família. } \\
\text { Promove ativamente o bem-estar de crianças, adolescentes, famílias e comunidades. } \\
\text { Concilia tecnologia (cuidado tecnológico) com valores associados ao cuidado ético-relacional, } \\
\text { que envolve o exercício da sensibilidade e da afetividade (estar perto, confortar, proteger, } \\
\text { respeitar a dignidade, a integridade, a autonomia, entre outros). }\end{array}$ \\
\hline $\begin{array}{l}\text { Desenvolve uma } \\
\text { prática de enfermagem } \\
\text { pediátrica sustentada na } \\
\text { ética profissional. }\end{array}$ & $\begin{array}{l}\text { - Demonstra conhecimento das normas de conduta e das bases para a atuação legal e ética da } \\
\text { enfermagem e do enfermeiro pediatra. } \\
\text { - Demonstra sensibilidade ética: capacidade de reconhecer um problema ético ou os aspectos } \\
\text { éticos das situações, capacidade de interpretar as reações e sentimentos da criança, do } \\
\text { adolescente e da familia; capacidade de decidir com inteligência e compaixão com base nos } \\
\text { entendimentos dos códigos de conduta ética, aprendizado acadêmico e autoconhecimento, } \\
\text { capacidade de reflexão, decisão e ação responsável. } \\
\text { - Demostra capacidade de reflexão ética: escolhe, busca e problematiza entre as várias } \\
\text { soluções possíveis, considerando os critérios de eficiência, eficácia e segurança, mas } \\
\text { também o equilibrio entre custo e benefício, sobretudo as demandas de prioridade, equidade } \\
\text { e moralidade. } \\
\text { - Adota um comportamento ético: conduta geral reiterada, saber-fazer qualificado e } \\
\text { corporificado de se relacionar com os outros de maneira respeitosa, receptiva e que apoia } \\
\text { suas preocupações. } \\
\text { - Identifica e relata casos de prática insegura e má conduta profissional. } \\
\text { - Registra de forma adequada os cuidados prestados e usa documentação apropriada. }\end{array}$ \\
\hline $\begin{array}{l}\text { Atua com } \\
\text { Responsabilidade Social }\end{array}$ & $\begin{array}{l}\text { - Reconhece que as crianças, os adolescentes e suas famílias podem ser prejudicadas por sua } \\
\text { condição de saúde ou social. } \\
\text { - } \text { Apresenta conduta ética e bioética diante dos problemas de saúde. } \\
\text { Reconhece a vulnerabilidade da criança, do adolescente e da familia e mobiliza recursos e } \\
\text { apoio, implementando ações de proteção e facilitação do acesso aos serviços sociais. } \\
\text { - Atua como mediador no processo de cuidar das crianças e dos adolescentes: respeita, } \\
\text { protege, defende a saúde das crianças e dos adolescentes e apoia suas familias e os contatos } \\
\text { com os serviços de saúde. } \\
\text { - Atua como agente facilitador na resolução de injustiças e iniquidades com base no } \\
\text { conhecimento e no papel que desempenha dentro do sistema social e de saúde. }\end{array}$ \\
\hline $\begin{array}{l}\text { Toma decisões pautadas } \\
\text { na ética }\end{array}$ & $\begin{array}{l}\text { - Toma decisões orientadas pelo conceito de "melhor interesse" da criança, do adolescente que } \\
\text { envolve a avaliação do equilibrio proporcional entre os benefícios e os potenciais danos. } \\
\text { - Considera os interesses da familia e a trata com seriedade. } \\
\text { - Pauta suas ações nos princípios da bioética. } \\
\text { - Concilia as necessidades dos outros (especialmente da familia) com as da criança e do } \\
\text { adolescente. } \\
\text { - Promove a "voz da criança e do adolescente", considerando a perspectiva da criança e } \\
\text { respeitando suas preferências. } \\
\text { - Presta informações adaptadas à capacidade de compreensão da criança, do adolescente e } \\
\text { respeita o direito ao consentimento de forma independente ou assentimento. } \\
\text { Fornece informações à criança a ao adolescente e à família para que possam compreender os } \\
\text { papéis/ funções dos membros da equipe de saúde e enfermagem e a assistência oferecida. } \\
\text { Toma decisão compartilhada com a criança, o adolescente, a família e outros profissionais de } \\
\text { saúde por meio de busca de entendimentos comuns. Estes entendimentos comuns fornecem } \\
\text { as bases para o desenvolvimento de acordos de cuidado, reforçando simultaneamente o } \\
\text { engajamento e a qualidade do relacionamento entre paciente, famîlia e equipe de saúde). }\end{array}$ \\
\hline
\end{tabular}




\section{Domínio 2: Prática clínica}

Definição: combinação de habilidades, conhecimentos e atitudes que o enfermeiro pediatra deve ter para desempenhar as funções de sua competência na oferta do cuidado direto, seguro e de qualidade a criança e/ou adolescente e família, considerando-o em sua integralidade dentro do contexto clínico específico. Constitui-se ainda na capacidade de avaliar com precisão e criticamente as melhores opções de cuidado pautadas nas políticas públicas de saúde, na prática baseada em evidências e no emprego do raciocínio clínico, ao mesmo tempo em que incorpora atributos como comunicação eficaz, gerenciamento eficiente do tempo e delegação de demandas a outros profissionais da equipe quando necessário.

\begin{tabular}{|c|c|}
\hline Competências essenciais & Habilidades \\
\hline $\begin{array}{l}\text { Atua na prevenção de doenças e } \\
\text { agravos, educação e promoção da } \\
\text { saúde, recuperação, reabilitação } \\
\text { e/ou paliação da criança e } \\
\text { adolescente nos diferentes níveis } \\
\text { de complexidade e atenção dos } \\
\text { contextos nos quais trabalha. }\end{array}$ & $\begin{array}{l}\text { Demonstra conhecimento sobre as políticas e os programas de saúde voltados } \\
\text { às crianças e aos adolescentes brasileiros, assim como as principais doenças e } \\
\text { agravos que podem acometê-los nas suas etapas de desenvolvimento. } \\
\text { Reconhece vulnerabilidades, riscos potenciais, necessidades e problemas } \\
\text { de saúde individuais e coletivos considerando o processo saúde-doença } \\
\text { em suas diversas dimensões (sociocultural, psicoemocional, biológica e } \\
\text { ambiental). } \\
\text { - Avalia a criança e adolescente nas suas etapas de desenvolvimento } \\
\text { conforme orientações das políticas e programas nacionais voltados à saúde } \\
\text { dessa população. } \\
\text { Promove o cuidado integral de crianças e de adolescentes por meio de } \\
\text { ações articuladas com os programas e políticas de promoção e proteção à } \\
\text { saúde, como recomendado pelo Ministério da Saúde do Brasil. } \\
\text { Realiza consultas de enfermagem direcionadas às situações de prevenção } \\
\text { de doenças e agravos, promoção, recuperação e reabilitação em saúde da } \\
\text { criança e do adolescente. } \\
\text { Emprega tecnologias leves e duras necessárias para execução das ações } \\
\text { de prevenção de doenças e agravos, educação e promoção da saúde, } \\
\text { recuperação, reabilitação e/ou paliação da criança e do adolescente. } \\
\text { Desenvolve atividades que promovam a educação e o conhecimento de } \\
\text { crianças, adolescentes, famílias e comunidades sobre aspectos relevantes } \\
\text { do seu processo de saúde-doença. } \\
\text { Contribui para o planejamento e a organização do seu contexto de trabalho. } \\
\text { Mantém, sempre que possível e necessário, articulação com os serviços de } \\
\text { referência e contrarreferência. } \\
\text { Promove e favorece a participação e decisão da família ( junto com a } \\
\text { criança/adolescente) no processo de educação e promoção da saúde, } \\
\text { recuperaçãa, reabilitação e/ou paliação da criança e do adolescente a fim } \\
\text { de alcançar o seu bem-estar. } \\
\text { Estabelece uma relação de ajuda com a criança, adolescente e família, por } \\
\text { meio da comunicação efetiva, de medidas para alivio do sofrimento e apoio } \\
\text { aos familiares frente à morte, no sentido de promover melhorias na sua } \\
\text { qualidade de vida. }\end{array}$ \\
\hline $\begin{array}{l}\text { Desenvolve raciocínio e julgamento } \\
\text { clínicos e pensamento crítico para } \\
\text { planejar e implementar o cuidado de } \\
\text { enfermagem baseado em evidências } \\
\text { científicas e nas políticas públicas } \\
\text { de saúde da criança e adolescente. }\end{array}$ & $\begin{array}{l}\text { Utiliza ferramentas do cuidado a exemplo do pensamento crítico, prática } \\
\text { reflexiva, pesquisa, auditoria e avaliação. } \\
\text { Desenvolve a prática clínica, a tomada de decisão e a resolução de } \\
\text { problemas baseados em evidências científicas e nas políticas públicas de } \\
\text { saúde da criança/adolescente. } \\
\text { Demonstra habilidade no uso de ferramentas eletrônicas e processamento } \\
\text { de dados para o cuidado de enfermagem. }\end{array}$ \\
\hline $\begin{array}{l}\text { Promove a Sistematização da } \\
\text { Assistência de Enfermagem (SAE) } \\
\text { para o } \\
\text { cuidado da criança e adolescente } \\
\text { no processo saúde-doença. }\end{array}$ & $\begin{array}{l}\text { Emprega as etapas do processo de Enfermagem para SAE, a partir } \\
\text { de pressupostos teórico metodológicos, a fim de promover o cuidado } \\
\text { qualificado. } \\
\text { - Garante que a documentação escrita (registros) seja clara, concisa, } \\
\text { oportuna e em conformidade com os protocolos e diretrizes institucionais. } \\
\text { Reconhece as necessidades e problemas de saúde da criança e do } \\
\text { adolescente; planeja, promove e avalia o cuidado em suas diversas dimensões } \\
\text { (sociocultural, psicoemocional, biológica e ambiental) por meio da SAE. } \\
\text { Desenvolve instrumentos que auxiliem e padronizem a assistência na SAE. }\end{array}$ \\
\hline
\end{tabular}


Continuação.

\begin{tabular}{|c|c|}
\hline Competências essenciais & Habilidades \\
\hline $\begin{array}{l}\text { Segue as diretrizes e protocolos da } \\
\text { Política Nacional de Segurança do } \\
\text { Paciente (PNSP). }\end{array}$ & $\begin{array}{l}\text { Demonstra conhecimento sobre a PNSP. } \\
\text { Desenvolve suas práticas de cuidado pautadas nas diretrizes e protocolos } \\
\text { da PNSP para promover a segurança do paciente pediátrico nos serviços de } \\
\text { atenção à saúde. }\end{array}$ \\
\hline $\begin{array}{l}\text { Demonstra proficiência técnica e } \\
\text { domínio das especificidades do } \\
\text { cuidado a criança e adolescente nos } \\
\text { espaços de atenção em que atua. }\end{array}$ & $\begin{array}{l}\text { Demonstra conhecimento abrangente de enfermagem na saúde da criança, } \\
\text { e/ou adolescente, baseado em evidências e apoiado na utilização do } \\
\text { conhecimento apreendido na área de formação e na experiência clínica. } \\
\text {. Demonstra domínio nas habilidades clínicas especializadas para promover a } \\
\text { assistência, assim como, de habilidades técnicas para gerenciar tecnologias } \\
\text { leves e duras necessárias no seu espaço de cuidado. } \\
\text { - Segue normas e protocolos de atendimento específicos para o cuidado } \\
\text { a criança e/ou adolescente, construídos conforme a necessidade dos } \\
\text { distintos níveis de atenção do sistema de saúde e com a finalidade de } \\
\text { organizar a assistência, padronizar as ações e alcançar a qualidade do } \\
\text { cuidado prestado. } \\
\text { Desempenha atividades de cuidado para com a criança e família privativas } \\
\text { do enfermeiro e supervisiona aquelas delegadas aos demais membros da } \\
\text { equipe: }\end{array}$ \\
\hline $\begin{array}{l}\text { Articula saberes interdisciplinares } \\
\text { necessários à execução do cuidado } \\
\text { à criança e ao adolescente. }\end{array}$ & $\begin{array}{l}\text { Estabelece a comunicação necessária e efetiva com os membros da sua } \\
\text { equipe, com os outros profissionais do seu serviço e dos demais serviços } \\
\text { de atenção do sistema de saúde, com os gestores e com os setores } \\
\text { da sociedade, como estratégia para articular os saberes em prol do } \\
\text { planejamento do cuidado voltado à criança no seu processo saúde-doença. }\end{array}$ \\
\hline $\begin{array}{l}\text { Estabelece relações interpessoais } \\
\text { e comunica-se com o paciente, a } \\
\text { família e a equipe multiprofissional } \\
\text { a fim de promover alinhamento do } \\
\text { plano } \\
\text { terapêutico e estimular o vínculo } \\
\text { entre família, } \\
\text { paciente e equipe. }\end{array}$ & $\begin{array}{l}\text { - Utiliza comunicação efetiva, escuta ativa e relações respeitosas com a } \\
\text { criança/adolescente, família e equipe multiprofissional na prestação do } \\
\text { cuidado em todos os níveis de atenção à saúde. } \\
\text { - Estabelece o diálogo com a equipe multiprofissional para promoção do } \\
\text { planejamento terapêutico adequado. } \\
\text { - Utiliza recursos lúdicos como estratégia de comunicação e expressão para } \\
\text { com as crianças. } \\
\text { Desenvolve o trabalho em equipe e estabelece relação com profissionais de } \\
\text { outros setores do sistema de saúde. }\end{array}$ \\
\hline $\begin{array}{l}\text { Promove o direito da criança e do } \\
\text { adolescente brincar, como fonte de } \\
\text { desenvolvimento físico, cognitivo, } \\
\text { social e emocional. }\end{array}$ & $\begin{array}{l}\text { Incentiva e promove o conhecimento sobre a importância do brincar na } \\
\text { infância. } \\
\text { cuidado, possibilitando ambientes que facilitem as brincadeiras adequadas } \\
\text { às faixas etárias. } \\
\text { Utiliza o brincar e a distração como medida não farmacológica para o alívio } \\
\text { da dor e ansiedade frente a procedimentos desconhecidos e dolorosos. } \\
\text { Utiliza o brinquedo terapêutico de forma sistematizada no cuidado, para } \\
\text { dar voz à criança e sua família, bem como, prepará-los para procedimentos } \\
\text { clínicos e hospitalização. }\end{array}$ \\
\hline $\begin{array}{l}\text { Promove o cuidado ético, legal, } \\
\text { seguro, com qualidade, equidade } \\
\text { e diversidade à criança, ao } \\
\text { adolescente e família em seus } \\
\text { contextos de cuidado. }\end{array}$ & $\begin{array}{l}\text { Demonstra consciência e respeito pelos direitos legais das crianças/ } \\
\text { adolescentes. } \\
\text {. Respeita os princípios da bioética. } \\
\text { Emprega o lúdico como mecanismo protetivo e promotor do } \\
\text { desenvolvimento infantil saudável. }\end{array}$ \\
\hline $\begin{array}{l}\text { Planeja, realiza e avalia ações de } \\
\text { educação e vigilância em saúde de } \\
\text { maneira compartilhada com } \\
\text { a criança e/ou adolescente, família } \\
\text { e/ou coletividade, visando à } \\
\text { construção de conhecimentos para } \\
\text { o autocuidado, o cuidado do outro, } \\
\text { mudanças no estilo e condições de } \\
\text { vida e para estimular a participação } \\
\text { e o controle social em saúde. }\end{array}$ & $\begin{array}{l}\text { Desenvolve ações de educação e vigilância em saúde para criança, } \\
\text { adolescente e suas famílias nos cenários de atenção, de acordo com as } \\
\text { suas necessidades individuais e/ou coletivas. } \\
\text { Utiliza estratégias pedagógicas com base no diálogo e na escuta ativa, } \\
\text { aplicando-as por meio de atividades lúdicas participativas de acordo com a } \\
\text { faixa etária. }\end{array}$ \\
\hline
\end{tabular}

\section{Domínio 3: Gestão, Liderança e Trabalho em equipe}

Definição: capacidade de organizar equipes e serviços de saúde infantil. O domínio inclui as competências que indicam a capacidade de comunicação dentro das estruturas organizacionais e monitorar e organizar a entrega de cuidados de saúde eficazes para crianças, adolescentes e famílias. As competências também 
podem incluir a participação no desenvolvimento de normas, políticas e atividades de qualidade específicas para a saúde de crianças, adolescentes e famílias.

\begin{tabular}{|c|c|}
\hline Competências essenciais & Habilidades \\
\hline $\begin{array}{l}\text { Comanda, dirige, influencia e } \\
\text { motiva pessoas e grupos de forma } \\
\text { positiva no intuito de alcançar um } \\
\text { objetivo em comum estimulando a } \\
\text { iniciativa e responsabilização. }\end{array}$ & $\begin{array}{l}\text { - } \text { Promove o senso grupal de participação e colaboração mútua. } \\
\text { a serem realizadas e compartilhando as responsabilidades com a equipe. } \\
\text { - } \text { Orienta e supervisiona a equipe de enfermagem. } \\
\text { - Estimula o aprimoramento da equipe por meio da Educação permanente. } \\
\text { - } \text { Apresenta relatório mensal sobre indicadores de qualidade da assistência, } \\
\text { propondo junto com a equipe estratégias de melhorias. } \\
\text { Propõe escalas diárias e mensais da equipe de enfermagem, distribuindo os } \\
\text { profissionais segundo seus conhecimentos, habilidades e atitudes. } \\
\text { enfermagem. } \\
\text { - Participa de ação política em nível local, estadual ou nacional para promover } \\
\text { a saúde de crianças, adolescentes e famílias. } \\
\text { Participa na tomada de decisão em grupo. } \\
\text { Compreende os padrões profissionais da prática, a avaliação da prática e a } \\
\text { responsabilidade pelo resultado da prática. }\end{array}$ \\
\hline $\begin{array}{l}\text { Gerencia os profissionais, } \\
\text { adotando modelos de gestão } \\
\text { que corroborem para o } \\
\text { desenvolvimento da equipe, } \\
\text { identificando suas competências } \\
\text { e organizando o seu processo de } \\
\text { trabalho; } \\
\text { Além disso, administra os recursos } \\
\text { materiais e financeiros, como } \\
\text { aquisição, distribuição, alocação } \\
\text { e faturamento adequado dos } \\
\text { recursos para a organização dos } \\
\text { serviços de saúde com o intuito } \\
\text { de garantir atendimento de } \\
\text { qualidade ao usuário. }\end{array}$ & 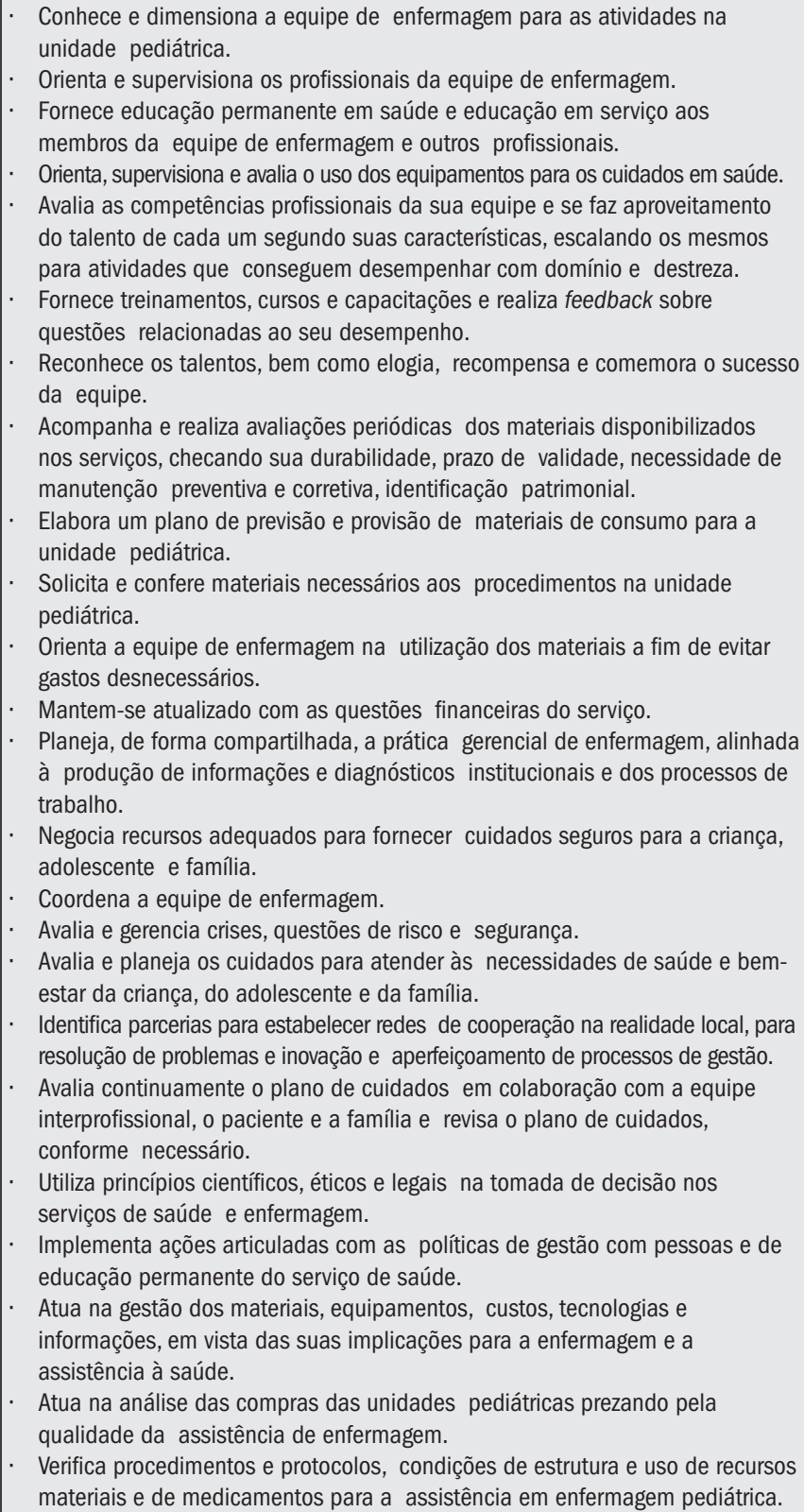 \\
\hline
\end{tabular}


Continuação.

\begin{tabular}{|c|c|}
\hline Competências essenciais & Habilidades \\
\hline $\begin{array}{l}\text { Realiza atividades em conjunto } \\
\text { com outros profissionais que } \\
\text { possuem diferentes funções e } \\
\text { papéis, procurando articulá-los } \\
\text { entre si para o cuidado integral } \\
\text { da criança e do adolescente. }\end{array}$ & $\begin{array}{l}\text { - Articula-se com as diferentes equipes em prol do cuidado integral, seguro e de } \\
\text { qualidade da criança e do adolescente. } \\
\text { Interage com diferentes equipes dentro e fora do serviço, segundo as } \\
\text { necessidades da criança, do adolescente e da família. } \\
\text { que pertence. } \\
\text { Eompartilha informações e conhecimentos pertinentes ao serviço e colocar-se } \\
\text { a disposição para ajudar sua equipe e as demais. } \\
\text { Contribui para o fortalecimento da cultura de grupo mantendo um bom } \\
\text { ambiente de trabalho. } \\
\text { Orienta a equipe de enfermagem quanto aos cuidados que deverão ser } \\
\text { efetivados ao paciente visando sua recuperação. } \\
\text { Delega responsabilidades à equipe e supervisiona o serviço prestado à } \\
\text { criança e ao adolescente. } \\
\text { Participa de processos de autoavaliação, demonstrando assertividade, } \\
\text { flexibilidade, confiança e sensibilidade aos efeitos da mudança. } \\
\text { Demonstra participação efetiva em equipes interdisciplinares } \\
\text { Demonstra habilidades efetivas para organizar, participar e liderar grupos. } \\
\text { Reconhece os aspectos subjetivos, técnico científicos, ético-políticos e } \\
\text { socioeducativos dos processos de trabalho em saúde e, especificamente, em } \\
\text { enfermagem. } \\
\text { Emprega a comunicação nos processos de trabalho em saúde e em enfermagem. } \\
\text { Participa politicamente em todos os processos de trabalho, de modo a garantir } \\
\text { condica necessárias ao desenvolvimento da autonomia e cidadania dos }\end{array}$ \\
\hline
\end{tabular}

\section{Domínio 4: Pesquisa e produção de conhecimento}

Definição: refere-se aos métodos científicos e às exigências ético-legais na produção de saberes em saúde e enfermagem. Indicam a capacidade de buscar materiais científicos bem como socializá-los e utilizá-los criticamente na prática, fortalecendo a implementação de boas práticas e o compartilhamento de sua produção do conhecimento com a comunidade acadêmica e sociedade em geral, ampliando o desenvolvimento da ciência da enfermagem.

\begin{tabular}{|c|c|}
\hline Competências Essenciais & Habilidades \\
\hline $\begin{array}{l}\text { Apresenta domínio da busca, leitura } \\
\text { e análise de textos científicos. }\end{array}$ & $\begin{array}{l}\text { - Acessa conhecimentos já produzidos sobre o problema a ser estudado por } \\
\text { meio de pesquisas em bases de dados científicas e acadêmicas. } \\
\text { - } \text { Desenvolve pensamento crítico-reflexivo. } \\
\text { - Interpreta os dados científicos disponíveis. } \\
\text { - } \text { manalisa e discute os achados das pesquisas com base nas evidências de } \\
\text { - Realiza revisões de literatura relacionadas às questões clínicas pediátricas e } \\
\text { de saúde infantil. }\end{array}$ \\
\hline $\begin{array}{l}\text { Realiza observação crítica e } \\
\text { investigativa da realidade. }\end{array}$ & $\begin{array}{l}\text { - Reconhece e problematiza as situações prioritárias da realidade profissional } \\
\text { que demandam a produção de conhecimento científico. } \\
\text { - Discute no âmbito coletivo os problemas e potenciais soluções a serem } \\
\text { investigadas e obtidas por meio da pesquisa. } \\
\text { - Adota postura investigativa para nortear a prática clínica. }\end{array}$ \\
\hline $\begin{array}{l}\text { Demonstra criatividade para } \\
\text { propostas de melhoria do cuidado e } \\
\text { rotinas nas áreas em que atua. }\end{array}$ & $\begin{array}{l}\text { - Considera e sintetiza as sugestões do coletivo (profissionais e usuários) para } \\
\text { implementação de melhores práticas nas ações em saúde. } \\
\text { - Identifica exemplos de projetos de intervenção exitosos e analisa viabilidade } \\
\text { de implementação em seu contexto, adaptando à sua realidade. }\end{array}$ \\
\hline $\begin{array}{l}\text { Busca atualização constante de } \\
\text { seus saberes e de sua equipe por } \\
\text { meio de evidências científicas. }\end{array}$ & $\begin{array}{l}\text { Fundamenta a sua prática em evidências científicas, tendo em vista a sua } \\
\text { incorporação no cotidiano do trabalho. } \\
\text { - Utiliza instrumentos científicos e metodológicos para resolução dos } \\
\text { problemas identificados na realidade. } \\
\text { Socializa o conhecimento produzido nos diversos cenários como serviços de } \\
\text { saúde, comunidade acadêmica e sociedade em geral. } \\
\text { - Discute suas ideias de maneira fundamentada e acolhe críticas e } \\
\text { sugestões para a melhoria do estudo, com habilidades de argumentação e } \\
\text { reconhecimento da importância da construção coletiva do conhecimento. } \\
\text { Realiza leitura de artigos publicados em periódicos/revistas científicas. }\end{array}$ \\
\hline
\end{tabular}


Continuação.

\begin{tabular}{|l|l|}
\hline Competências Essenciais & Habilidades \\
\hline $\begin{array}{l}\text { Produz evidências científicas a partir } \\
\text { de métodos e práticas de pesquisa. }\end{array}$ & $\begin{array}{l}\text { Embasa sua produção do conhecimento considerando as demandas de seu } \\
\text { contexto de atuação. } \\
\text { Participa de projetos de pesquisa, quando disponíveis no contexto de } \\
\text { atuação, nas diferentes etapas, utilizando método científico e princípios } \\
\text { éticos para a produção do conhecimento. } \\
\text { Desenvolve textos baseados em evidências científicas para suporte de } \\
\text { atividades de educação, assistência e gestão. }\end{array}$ \\
\hline $\begin{array}{l}\text { Protege os direitos das crianças, } \\
\text { dos adolescentes e das famílias } \\
\text { envolvidos em pesquisa e/ou } \\
\text { outras intervenções. }\end{array}$ & $\begin{array}{l}\text { Conduz ações em pesquisa envolvendo crianças, adolescentes e famílias } \\
\text { com ética e suporte, considerando a vulnerabilidade da população } \\
\text { infantil. } \\
\text { Obtém consentimento verbal e por escrito dos pais e assentimento } \\
\text { das crianças e dos adolescentes, quando aplicável, antes de iniciar a } \\
\text { pesquisa. }\end{array}$ \\
\hline
\end{tabular}

\section{Domínio 5: Prática educativa}

Definição: inclui o engajamento em atividades de educação permanente em saúde e continuada no ambiente de trabalho direcionadas a si próprio, a colegas de trabalho e estudantes, utilizando as habilidades de aprendizagem com autonomia. Realiza ações de educação em saúde em todos os contextos, articulando o uso de diferentes abordagens, estratégias e tecnologias para garantir melhor eficácia da troca de informações com a população infantil e família sobre saúde.

\begin{tabular}{|c|c|}
\hline Competências essenciais & Habilidades \\
\hline $\begin{array}{l}\text { Busca constantemente aprimorar os } \\
\text { conhecimentos para subsidiar sua } \\
\text { prática. }\end{array}$ & $\begin{array}{l}\text { - Utiliza estratégias de busca e análise de materiais de estudo. } \\
\text { - } \text { Constrói constantemente novos saberes. } \\
\text { o avanço de da carreira do enfermeiro pediatra. } \\
\text { - Investe em constante atualização na área da pediatria e afins. }\end{array}$ \\
\hline $\begin{array}{l}\text { Fomenta ações de educação permanente } \\
\text { em saúde e de educação continuada } \\
\text { junto aos colegas de trabalho. }\end{array}$ & $\begin{array}{l}\text { Reconhece as potencialidades e dificuldades da equipe de enfermagem } \\
\text { relacionadas com o desenvolvimento de suas competências } \\
\text { profissionais. } \\
\text { Identifica o processo de trabalho na equipe multiprofissional e promove } \\
\text { estudos de aprimoramento com foco na criança, no adolescente e sua } \\
\text { família. } \\
\text { Age na perspectiva construtivista da educação, reconhecendo } \\
\text { as vantagens da construção coletiva do saber, do uso das } \\
\text { metodologias ativas, baseadas nos desafios do contexto do } \\
\text { trabalho, pautadas na valorização dos pares e nas evidências } \\
\text { científicas. } \\
\text { culdera e encoraja outras lideranças para estabelecer e fortalecer a } \\
\text { envolvimento e a motivação dos pares. } \\
\text { entucacana promovendo ativamente o } \\
\text { assertividade, flexibilidade, confiança e sensibilidade aos efeitos da } \\
\text { mudança. } \\
\text { Demonstra compromisso ativo para continuar o desenvolvimento de } \\
\text { sua própria educação e formação profissional. } \\
\text { Identifica as necessidades de aprendizagem da equipe que } \\
\text { surgem no cotidiano do cuidado à criança, ao adolescente e seus } \\
\text { familiares. } \\
\text { Incorpora os resultados dos processos de avaliação de desempenho } \\
\text { em sua própria prática. } \\
\text { Contribui para as experiências de aprendizagem de estudantes e novos } \\
\text { funcionários por meio de preceptoria/mentoria. } \\
\text { Contribui para as experiências de aprendizagem e desenvolvimento } \\
\text { profissional de si e dos outros. }\end{array}$ \\
\hline
\end{tabular}


Continuação.

\begin{tabular}{|c|c|}
\hline Competências essenciais & Habilidades \\
\hline Realiza educação em saúde. & $\begin{array}{l}\text { - Planeja ações individuais e coletivas de educação em saúde, de } \\
\text { acordo com o contexto e demandas da população. } \\
\text { - Coordena atividades de educação/promoção da saúde de forma } \\
\text { eficaz. } \\
\text { - Cria e organiza espaços de aprendizado para crianças, adolescentes e } \\
\text { familiares. } \\
\text { Identifica as necessidades de aprendizagem relacionadas à saúde das } \\
\text { crianças, dos adolescentes e seus familiares. } \\
\text { - Reconhece os fatores que afetam a saúde e as ações apropriadas a } \\
\text { serem tomadas para a promoção da saúde } \\
\text { Fornece à criança, ao adolescente e à família informações e opções } \\
\text { que lhes permitam adotar decisões conscientes. } \\
\text { Ajuda a criança, o adolescente e a família a reconhecer e compreender } \\
\text { o estado de saúde atual e as mudanças na saúde. } \\
\text { Avalia a prontidão da criança, do adolescente e familiares para } \\
\text { aprender e fornece tempo suficiente para ensinar de forma eficaz. } \\
\text { Valoriza o saber popular e dialoga com ele à luz das evidências } \\
\text { científicas, visando à autonomia do cuidado à saúde das crianças, dos } \\
\text { adolescentes e das suas famílias. } \\
\text { Utiliza abordagens, estratégias e tecnologias diversas para promover } \\
\text { aprendizagem em saúde para que crianças, adolescentes e familiares } \\
\text { realizem os cuidados necessários. } \\
\text { Trabalha em parceria com outros profissionais de saúde, agentes } \\
\text { comunitários de saúde, clientes, famílias e a comunidade na } \\
\text { prevenção de doenças, promoção e proteção da saúde da criança e do } \\
\text { adolescente. }\end{array}$ \\
\hline $\begin{array}{l}\text { Promove comunicação clara e eficaz nos } \\
\text { processos educativos, favorecendo a } \\
\text { construção de conhecimento. }\end{array}$ & $\begin{array}{l}\text { - Utiliza linguagem adequada ao entendimento de acordo com o nível de } \\
\text { compreensão e proficiência de crianças, adolescentes e dos membros } \\
\text { da família, possibilitando-lhes tomadas de decisões conjuntas. } \\
\text { - Alinha comunicação não verbal à comunicação verbal. } \\
\text { - Valoriza na comunicação, o tom de voz e a postura corporal adequados, } \\
\text { equilíbrio entre ações de ouvir e falar, escuta ativa, esclarecimento } \\
\text { de dúvidas e feedback, valoriza as diferentes culturas e considera o } \\
\text { contexto de ambiência. } \\
\text { - Reconhece as famílias como parceiros da equipe de saúde no } \\
\text { planejamento dos cuidados e utiliza as habilidades de comunicação } \\
\text { para produzir os melhores resultados em saúde. } \\
\text { Realiza registro completo das condições de saúde das crianças e dos } \\
\text { adolescentes em prontuário, contemplando aspectos que envolvam a } \\
\text { família nas anotações. }\end{array}$ \\
\hline
\end{tabular}

\section{Referências}

1. Barry MM, Battel-Kirk B, Dempsey C. The CompHP core competencies framework for health promotion in Europe. Health Educ Behav. 2012;39(6):648-62.

2. Brasil. Ministério da Saúde. Secretaria de Atenção à Saúde. Departamento de Ações Programáticas Estratégicas. Política Nacional de Atenção Integral à Saúde da Criança: orientações para implementação/ Ministério da Saúde. Brasília (DF): Ministério da Saúde; 2018.

3. Conselho Federal de Enfermagem (COFEN). Resolução COFEN - 564/2017 de 5 de abril de 2018. Aprova o novo Código de Ética dos Profissionais de Enfermagem. Diário Oficial da União. Brasília (DF): COFEN; 2017. Disponível em: http://www.cofen.gov.br/entra-emvigor-novo-codigo-de-etica-da-enfermagem-brasileira_61770.html

4. Conselho Federal de Enfermagem (COFEN). Resolução COFEN - 581/2018 de 11 de julho de 2018. Atualiza, no âmbito do Sistema COFEN/ Conselhos Regionais de Enfermagem, os procedimentos para Registro de Títulos de Pós-Graduação Lato e Stricto Sensu concedido a Enfermeiros e aprova a lista das especialidades. Diário Oficial da União. Brasília (DF): COFEN; 2018. Disponível em: http://www.cofen. gov.br/resolucao-cofen-no-581-2018_64383.html

5. Brasil. Presidência da República. Constituição da República Federativa do Brasil. Braśilia: Ed Senado; 1988.

6. Brasil. Ministério da Saúde. Estatuto da Criança e do Adolescente. Brasília (DF): Ministério da Saúde; 2006. 96 p.

7. Institute for Patient and Family Centered Care (IPFCC). What is patient and family-centered care? Institute for Patient and Family Centered Care. McLean: IPFCC; 2018.

8. Brasil. Ministério da Saúde. Política Nacional de Humanização. Brasília (DF): Ministério da Saúde, 2013.

9. Conselho Federal de Enfermagem (COFEN). Resolução COFEN - 546/2017 de 9 de maio de 2017. Atualiza norma para utilização da técnica do Brinquedo/Brinquedo Terapêutico pela equipe de enfermagem na assistência à criança hospitalizada. Diário Oficial da União. Brasília (DF): COFEN; 2017. Disponível em: http://www.cofen.gov.br/resolucao-cofen-no-05462017_52036.html 
10. International Play Association Brasil. Artigo 31 da Convenção dos Direitos da Criança: 0 desenvolvimento infantil e 0 direito de brincar. São Paulo: IPA; 2015. 20p.

11. Brasil. Ministério da Saúde. Programa Nacional de Segurança do Paciente. Portaria n ${ }^{0} 529$, de 1 de abril de 2013. Brasília (DF): Ministério da Saúde; 2013.

12. Bagnasco A, Cadorin L, Barisone M, Bressan V, lemmi M, Prandi M, et al. Ethical dimensions of paediatric nursing: a rapid evidence assessment. Nurs Ethics. 2018;25(1):111-22.

13. International Council of Nurses (ICN). The ICN code of ethics for nurses. International Council of Nurses: Geneva: ICN; 2012.

14. Kulju K, Stolt M, Suhonen R, Leino-Kilpi H. Ethical competence: A concept analysis. Nurs Ethics. 2016;23(4):401-12.

15. Council of International Neonatal Nurses (COINN). International Neonatal Nursing Competency Framework. J Perinat Neonatal Nurs. 2019;25:258-64.

16. Mott S, Fogg N, Foote N, Hillier M, Lewis DA, McDowell BM, et al. Society of Pediatric Nurses' Core Competencies for the Pediatric Nurse. 2018:38:142-4.

17. The Nursing Council of Hong Kong (HKNC). Core-Competencies for Registered Nurses (Sick Children), 2015.

18. Coluci MZ,Alexandre NM, Milani D. Construção de instrumentos de medida na área da saúde. Cienc e Saude Coletiva. 2015;20(3):92536 .

19. Benson J, Clark F.A guide for instrument development and validation. Am J Occup Ther. 1982;36(12):789-800.

20. Massaroli A, Martini JG, Lino MM, Spenassato D, Massaroli R. Método Delphi como referencial metodológico para a pesquisa em enfermagem. Texto Contexto Enferm. 2017;26(4):e1110017.

21. Polit DF, Beck CT, Hungler BP. Fundamentos de Pesquisa em Enfermagem: avaliação de evidencias para a prática da enfermagem. 90 ed. São Paulo: Artmed; 2019. 